\title{
INVESTIGATION OF EGO AND TASK ORIENTATION AMONG INTERNATIONAL WRESTLING REFEREES
}

\author{
Barbas I. ${ }^{1}$, Bebetsos E. ${ }^{1}$, Christos K. ${ }^{2}$, Curby D. ${ }^{3}$, Mirzaei B. ${ }^{4}$ \\ ${ }^{1}$ Democritus University of Thrace, School of Physical Education \& Sport Science, Komotini, Greece \\ ${ }^{2}$ University of Athens, School of Physical Education \& Sport Science, Athens, Greece \\ ${ }^{3}$ International Network of Wrestling Researchers (INWR), USA \\ ${ }^{4}$ University of Guilan, Rasht, Iran
}

\begin{abstract}
Aim: study was to investigate any possible effect(s) of experiences from active membership and participation in task or ego orientations among referees in the sport of wrestling. Material: The sample consisted of 213 international referees from 30 countries (Greece, Turkey, Bulgaria, France, Italy, Germany, Sweden, Finland, Switzerland, Russia, Poland, Hungary, U.S.A, Ukraine, Armenia, Azerbaijan, Iran, Japan, Korea, Mongolia, Kazakhstan, Egypt, Canada, Georgia, Croatia, Uzbekistan, Norway, Cuba, Belarus, \& Tunisia). Their age ranged from 26 to 60 yrs. old $(M=43, S D=8.6)$. During the procedure, the participants were asked to fill a specific questionnaire, the «Task and Ego Orientation in Sport Questionnaire» (Duda \& Nicholls, 1992). Results: Results showed that the referees from elite wrestling level' countries (Russia, Azerbaijan, Iran, Turkey, Georgia, Armenia, Bulgaria, Ukraine, U.S.A., Korea, Japan, Kazakhstan, \& Cuba) are more task oriented than those from the non-elite wrestling level' countries. Researchers believe that this occurred because referees from non-elite wrestling level' countries might have less game-sport experience and more specifically in high level games. At the same time, the Olympic experience referees were more task oriented than the non-Olympic experienced. Conclusion: Referee's decisions are an important issue in the sport milieu. The investigations in decision-making by referees and factors that affect it are rather scarce and research should focus on such topics. Improvement of decision-making by referees, would lead to safer and better performance. Thus, better understanding of referees' behavior, through identification and operationalization of the factors affecting it, might lead to more effective selection, training and performance.
\end{abstract}

Key words: task orientations, referees, decision-making, wrestling.

\section{Introduction}

One of the factors which could assist in better comprehending referees' decisions is achievement orientation. In achievement motivation in sport, goals have been perceived as being related to the way individuals believe, feel or regulate their abilities [1, 8, 11-13]. Nicholls [14] claimed that goal orientation is related to a number of attitudes, convictions and values. In his theory he postulated the existence of two main goal orientations, task and ego, which are independent of each other but differ among individuals and across environments. Research has showed that a person with an ego orientation is more likely to approve improper sport behaviors and accept athletic aggression, while this does not hold true for persons with task orientation [5, 6]. Individuals with task orientation are more likely to choose moral than non-moral values when there is a conflict $[4,5]$ and to respect social conventions, personal commitment, the rules and officials [7].

Cross-sectional studies in the USA [3] and Greece [16] have indicated positive relationship between participation in sport and goal orientations, but it is still unclear whether this is the cause or effect of youngsters' involvement in sport. According to social learning theory [2], participation in sport is expected to cultivate youngsters' goals to further improve and demonstrate their sport abilities. Hence, the positive relationship between goal orientations and participation in sport, found in cross-sectional studies, could be ascribed to social learning effects of sport involvement on goal orientations, rather than the opposite. In addition, given the different opinions about the role of ego orientation in sport achievement [4, 9], the interactive effects of task and ego orientation should be also reported. One could possibly assume that the positive effects of task orientation on sport involvement are even stronger when they are accompanied by high ego orientation but they are undermined when

(c) Barbas I., Bebetsos E., Christos K.,

Curby D., Mirzaei B., 2016

doi:10.15561/20755279.2016.0606 
they are joined by low ego orientation [9], although some authors suggest that ego orientation has no benefits in youth sports [10].

Internationally minimal attempts were made in order to investigate any relations between goal orientation and any sport officials. As a result of that, the significant aspect of this study is the first attempt to investigate levels of goal orientation among international wrestling referees.

Hypothesis: The task orientations among international referees of wrestling depend on the development of the struggle in a particular country.

Aim: the study was to investigate any possible effect(s) of experiences from active membership and participation in task or ego orientations among referees in the sport of wrestling.

\section{Materials and Methods}

\section{Participants}

The sample consisted of 213 international referees from 30 countries (Greece, Turkey, Bulgaria, France, Italy, Germany, Sweden, Finland, Switzerland, Russia, Poland, Hungary, U.S.A, Ukraine, Armenia, Azerbaijan, Iran, Japan, Korea, Mongolia, Kazakhstan, Egypt, Canada, Georgia, Croatia, Uzbekistan, Norway, Cuba, Belarus, $\&$ Tunisia). Their age ranged from 26 to 60 yrs. old $(M=43, S D=8.6)$.

\section{Research Design}

During the procedure, the participants were asked to fill a specific questionnaire, the "Task and Ego Orientation in Sport Questionnaire" (Duda \& Nicholls, 1992). This questionnaire was translated into Greek with the use of the back-translation technique [15]. Apart from, this questionnaire was adapted from to Greek mentality and modified for referees [17]. There are two independent scales related to either Task or Ego Orientation. In its present form, each statement begins with "I feel more successful as a referee when ..." followed by 13 different endings. For example, the endings related to Task Orientation include "I learn to apply the rules correctly", "something I learn makes me want to referee even more", "learn something that helps me referee better by trying harder", "try really hard to referee well". For Ego Orientation, examples are "I am the only one who can referee a hard game", "I can do better than other referees", "other referees cannot do as well as I can", "other referees mess up while I do not", "my decisions are better than those of other referees". The respondent was asked to indicate how much he agreed with each of the 13 statements ( 7 of which relate to Task Orientation and 6 to Ego). Responses are given on a 5-point Likert scale with anchors of 5: strongly agree and 1: strongly disagree.

\section{Statistical Analysis}

Statistical analysis was performed with the help of programming package Statgraphics 5.1 (Manugistics, Inc.). The methods of parametric statistics of t-criterion of Student were applied.

\section{Results}

The results showed that using the Cronbach's coefficient $\alpha$ internal consistency for "Task" was .80 and for "Ego".84.

Although the analyses revealed no statistical significant differences among the sample, crosstabs indicated significant results. More specifically, the sample divided into 2 groups. Group 1, referees of Elite wrestling level' countries ( $\mathrm{N}=70)$, and Group 2, Non-elite $(\mathrm{N}=40)$. Results showed that the referees from Elite wrestling level' countries (Russia, Azerbaijan, Iran, Turkey, Georgia, Armenia, Bulgaria, Ukraine, U.S.A., Korea, Japan, Kazakhstan, \& Cuba) are more task oriented, than those from Non-elite wrestling level' countries. Researchers believe that this occurred because referees from non-elite wrestling level' countries might have less game-sport experience and more specifically in high level games (Fig. 1).

Also, the sample divided into 3 groups, according to their referring experience. Group 1 was referees with experience up to $11 \mathrm{yrs}$. $(\mathrm{N}=33)$, Group 2 from 12 up to 19 yrs. $(\mathrm{N}=34)$, and Group 3 from 20 yrs. and on $(\mathrm{N}=43)$. The results showed that referees with more experience are more Task oriented than the other 2 groups. Researchers believe that referees with more yrs. of experience are more into the "personal commitment" idea than less experienced ones (Figure 2). 

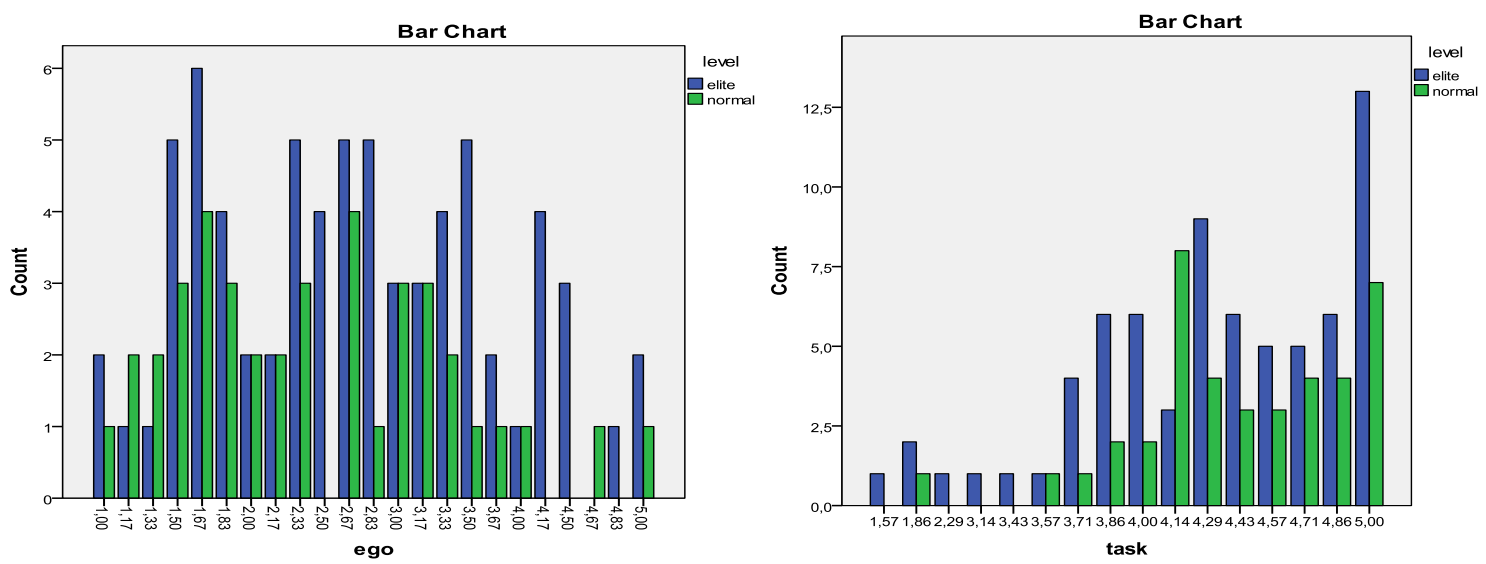

Figure 1. Elite and non-elite referees.
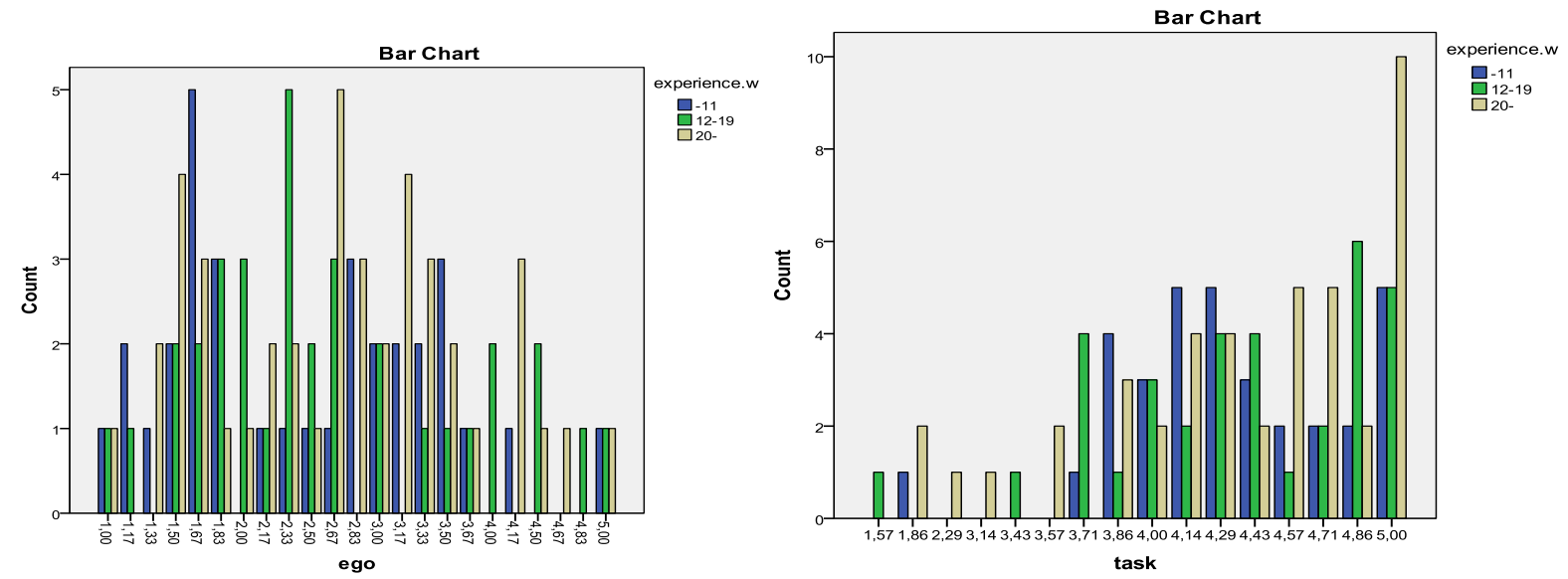

Figure 2. Levels of experience.

Finally, the sample divided into 2 groups according their Olympic Games' experience. Group 1, the Olympic referees $(\mathrm{N}=32)$, and Group 2 the Non-Olympic $(\mathrm{N}=78)$. The results showed that the Olympic experience referees were more Task oriented than the Non-Olympic experienced. These results are consistent with the previous ones (Figure 3).
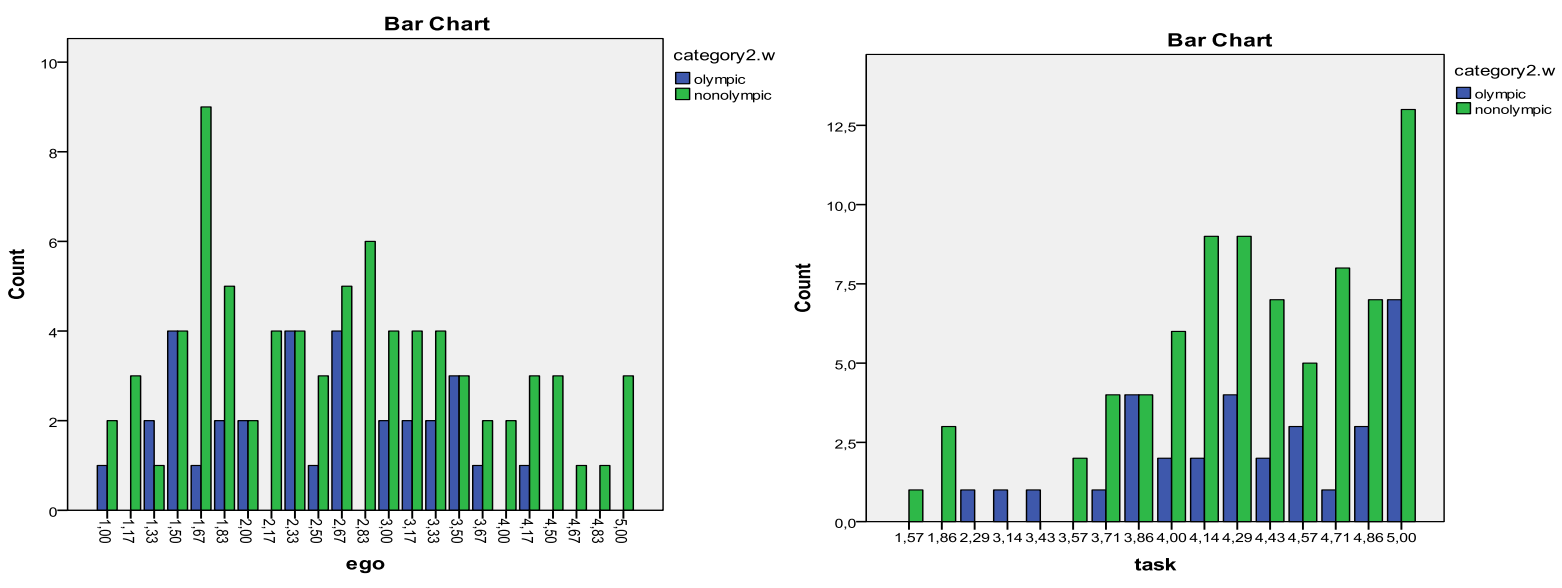

Figure 3. Olympic and Non-Olympic experience referees. 


\section{Discussion}

The results of this study support the positive role of perceived athletic competence, task orientation and intrinsic motivation in sport and exercise involvement. Further studies examining the mediator variables between sport and exercise involvement and task orientation, perceived competence and intrinsic motivation are called for $[8,12,13]$. It is important to understand the self regulation strategies trigger port and exercise behaviour $[2,4,5]$. Referee's decisions are an important issue in the sport milieu $[3,16]$. The investigations in decision-making by referees and factors that affect it are rather scarce and research should focus on such topics. Improvement of decision-making by referees, would lead to safer and better performance [10,14]. Finally, a better understanding of referees' behavior, through identification and operationalization of the factors affecting it, might lead to more effective selection, training and performance.

Finally, the causal relationship of sport and exercise involvement with goal orientations, perceived competence and intrinsic motivation must be investigated in different cultures to determine whether these socialcognitive variables have universal importance. Future research should be focused on comparison between referees (i.e. background difference, level difference, stress \& anxiety, attention, self-confidence) on different exercise levels and settings.

\section{Conclusions}

Referee's decisions are an important issue in the sport milieu. The investigations in decision-making by referees and factors that affect it are rather scarce and research should focus on such topics. Improvement of decision-making by referees, would lead to safer and better performance. Thus, better understanding of referees' behavior, through identification and operationalization of the factors affecting it, might lead to more effective selection, training and performance.

\section{Conflict of interests}

The authors declare that there is no conflict of interests.

\section{References}

1. Competitive, cooperative, and individualistic goal structures: A cognitive-motivational analysis. In: R. E. Ames y C. Ames (Eds.). Research on motivation in education, Nueva York: Academic; 1984.

2. Press.Bandura A. Social foundations of thought and action: A social cognitive theory. Englewood Cliffs, NJ: Prentice-Hall; 1986.

3. Duda JL. Goal perspectives, participation and persistence in sport. International Journal of Sport Psychology. 1989;20:42-56.

4. Duda JL. Perpetuating myths: A response to Hardy's 1996 Coleman Griffith Address. Journal of Applied Sport Psychology. 1997;9:307-313.

5. Duda JL, Olson LK, Templin TJ. The relationship of task and ego orientation to sportsmanship attitudes and the perceived legitimacy of injurious acts. Research Quarterly for Exercise and Sport. 1991; 62: 79-87.

6. Duda JL, Nicholls JG. Dimensions of achievement motivation in schoolwork and sport. Journal of Educational Psychology. 1992; 84: 290-299.

7. Dunn JGH, Dunn JC. Goal orientation, perceptions of aggression, and sportspersonship in elite male youth ice hockey players. The Sport Psychologist. 1999; 13: 183-200.

8. Dweck CS, Elliott E. Achievement motivation. In: E. Hetherington, (Ed.), Socialisation, personality, and social development. New York; 1983.

9. Hardy L. Three myths about applied consultancy work. Journal of Applied Sport Psychology. 1997; 9: 277294.

10. Liukkonen J, Telama R, Biddle S. Enjoyment in youth sports: A goal perspectives approach. European Yearbook of Sport Psychology. 1998; 2: 55-75.

11. Maehr M, Braskamp L. The motivation factor: a theory of personal investment. Lexington, MA: Lexington; 1986.

12. Nicholls JG. Achievement motivation: conceptions of ability, subjective experiences, task choice, and performance. Psychological Review. 1984; 91: 328-346. 
13. Nicholls JG. Conceptions of ability and achievement motivation. Research on motivation in education: student motivation. 1984; 1: 39-73.

14. Nicholls JG. The competitive ethos and democratic education. Cambridge, Mass: Harvard University Press; 1989.

15. Papaioannou A, McDonald A. I. Goals perspectives and purposes of physical education as perceived by Greek adolescents. Physical Education Review. 1993; 16: 41-48.

16. Papaioannou A. "I agree with the referee's abuse, that's how I also beat.. .": Prediction of sport violence and attitudes towards sport violence. European Yearbook of Sport Psycholog. 1997; 1: 113 - 129.

17. Proios M, Doganis G, Athanailidis I. Moral development and form of participation, type of sport, and sport experience. Perceptual and motor skills. 2004; 99(2): 633-642. 


\section{Information about the authors:}

Barbas loannis; http://orcid.org/0000-0001-7092-3255; imparmpa@phyed.duth.gr; Department of Physical Education and Sports Science, Democritus University of Thrace ; Vasilissis Sofias 12, Xanthi 67100, Greece.

Bebetsos Evangelos; http://orcid.org/0000-0002-3307-9021; empempet@phyed.duth.gr; Department of Physical Education and Sports Science, Democritus University of Thrace; Vasilissis Sofias 12, Xanthi 67100, Greece.

Christos Kollias; http://orcid.org/0000-0002-7171-1593; george.65@mail.ru; Department of Science Physical Education and Sport Sciences, University of Athens; 30, Panepistimiou Str., 10679, Panepistimio, Athens, Greece.

Curby David; http://orcid.org/0000-0003-1170-4583; davcurb@gmail.com; USA Wrestling Sport Science Committee; 1719 W. 60th St La Grange, Illinois, 60525, USA .

Mirzaei Bahman; http:// orcid.org/0000-0002-4615-7295; bmirzaei2000@yahoo.com; Faculty of Physical Education and Sport Sciences, University of Guilan; Khalij Fars highway, 5th kilo meter of Ghazvin road, Postal Code 4199613776, Rasht, Iran.

Cite this article as: Barbas I., Bebetsos E., Christos K., Curby D., Mirzaei B. Investigation of ego and task orientation among international wrestling referees. Physical education of students, 2016;6:49-54. doi:10.15561/20755279.2016.0606

The electronic version of this article is the complete one and can be found online at: http://www.sportpedu.org.ua/html/arhive-e.html

This is an Open Access article distributed under the terms of the Creative Commons Attribution License, which permits unrestricted use, distribution, and reproduction in any medium, provided the original work is properly cited (http://creativecommons.org/licenses/by/4.0/deed.en).

Received: 29.10.2016

Accepted: 10.11.2016; Published: 28.12.2016 